\title{
Indigenous Knowledge and Conservation of Medicinal Plants in Rungwe District, Tanzania
}

\author{
Suma F. Kibonde \\ Department of Geography and Environmental Studies, Solomon Mahlangu College of Science and Education, Sokoine University \\ of Agriculture, Chuo Kikuu, Morogoro, Tanzania \\ Email: kibondesuma9@yahoo.com
}

How to cite this paper: Kibonde, S.F. (2020) Indigenous Knowledge and Conservation of Medicinal Plants in Rungwe District, Tanzania. Open Access Library Journal, 7: e6545.

https://doi.org/10.4236/oalib.1106545

Received: June 22, 2020

Accepted: July 27, 2020

Published: July 30, 2020

Copyright $\odot 2020$ by author(s) and Open Access Library Inc.

This work is licensed under the Creative Commons Attribution International License (CC BY 4.0).

http://creativecommons.org/licenses/by/4.0/ (c) (i) Open Access

\begin{abstract}
Indigenous knowledge provides basis for local level decision making in natural resources conservation in rural communities. However, until recently little has been done to search for indigenous knowledge applied in conserving medicinal plants. This paper attempted to focus on indigenous knowledge used in natural resources; particularly medicinal plants in Rungwe District, Mbeya Region, Tanzania. Results revealed that selective harvesting of medicinal plant parts was popular by $94 \%$ of the respondents, followed by domestication of medicinal plant species (84\%). The study findings indicated that adults revealed significantly higher knowledge than youth $(\mathrm{p}=0.002)$ and the knowledge was significantly higher among male respondents than females $(p=0.031)$. Conclusively, the respondents showed to possess sound indigenous knowledge on conservation and their knowledge varied based on their socio-demographic attributes. In view of these findings, the study recommends for preservation and promotion of indigenous knowledge of conservation across the community. Likewise, there is a need of transmitting indigenous knowledge on conservation by the elders to the youth.
\end{abstract}

\section{Subject Areas \\ Plant Science}

\section{Keywords}

Conservation, Indigenous Knowledge, Sacred Forest, Conservation Strategy

\section{Introduction}

The role played by indigenous knowledge on conservation of medicinal plants is extensively acknowledged [1] [2]. However, according to [3] and [4] about 
15,000 medicinal plant species worldwide are under threats of extinction, implying that the earth loses at least one potential major drug species every two years. To overcome this challenge, several scholars have argued that conservation of medicinal plants should be a community centred through using their experiences that have been developed and transmitted over time involving verbal expressions and valuable practices on sustainable conservation of medicinal plans [5] [6] [7] [8]. In the same line [5] argued that community participation is essential for the attainment of the economic, political, social and environmental objectives that underpin conservation. According to [9] there is a link between indigenous knowledge and the management of environment in which medicinal plants grow. This means the sustainability of medicinal plants is in the hand of the community basing on their knowledge about the use and importance of them.

Traditional medicines are believed to be the most affordable solution for about $80 \%$ of the world's population as well as $75 \%$ of people living with HIV/AIDS in Africa [10] [11]. In Tanzania, traditional medicine serves up to $60 \%$ of primary healthcare [12] [13]. According to [14] Africa bears more than $24 \%$ of the worldwide burden of diseases, with only $3 \%$ of the health workers; and less than $1 \%$ of finance invested in health matters. It is also evidenced that the imbalance ratio of medical doctors to the population in Africa is one of the factors that promote the use of traditional medicine. For example, by 2010, the ratio of medical doctors to population was 1:40,000 while that of traditional healers to population was 1:500 [15] [16]. The recent data indicate that about $44 \%$ of WHO member states have less than one doctor per 1000 population [17]. Other factors that promote the use of traditional medicines include perceived effectiveness of traditional medicine in dealing with infections and/or diseases, cultural preferences by communities and belief that traditional medicine can easily offset side effects caused by using Antiretroviral therapies [18] [19]. However, the indigenous knowledge known to be used by people in conserving medicinal plants is underrated with little documentation.

The communities' reliance on plants for disease management and other livelihood strategies leave plants prone to depletion and extinction which in turn would cause misery to the large percentage of rural people who depend on them [13] [20]. Apart from overharvesting of medicinal plant species, other factors contributing to medicinal plants depletion in the study area included deforestation contributing to the total African forest loss [21] to be about 3,000,000 hectares/year. Tanzania in particular is reported to lose up to 150,000 hectares of forests annually [22]. One of the key factors behind this pace of losing important species of medicinal plants is not only the limited inclusion of indigenous knowledge in the conservation of medicinal plants but also weak succession of indigenous knowledge between old generation and new generation [23] [24]. Therefore, this paper was set to assess the knowledge gap surrounding the use of indigenous knowledge on conservation of medicinal plants to ensure their sustainability and the factors affecting indigenous knowledge use in conservation. The study also at- 
tempted to document and signify integration of the indigenous knowledge on conservation of medicinal plants for managing HIV/AIDS opportunistic infections. In achieving these objectives, the study borrows World Intellectual Property Rights [25]'s concepts such as: the traditional knowhow, innovations, information, practices and skills in its uses of the term indigenous knowledge.

This study was guided by Knowledge-practice-belief systems Theory as postulated by [26]. In this regard, knowledge is defined by many options including practices or strategies as well as belief systems that help conserve certain species [27]. In other words, the community has some beliefs and traditions that serve as recipes for sustainable utilization of biodiversity such as medicinal plants. These beliefs and traditions have been preserved as knowledge and practices of conservation among communities [26]. Moreover, the theory explains about complex relationships of knowledge, management practices and beliefs existing in the communities thereof.

\section{Methodology}

This study was conducted in Rungwe District, Mbeya Region, Tanzania. The district was selected because it is among the districts in the country endowed with rich natural resources such as many forests in which medicinal plants are found. The District is one among other areas which are affected by HIV/AIDS and people use medicinal plants for their primary health care including treatment of opportunistic infections. The study adopted a cross section research design in which data were collected once in a time. Data were collected from 293 respondents at households (5.2\%) which are considered adequate for such kind of studies. Data collection methods involved semi-structured questionnaire composed of both closed and open-ended questions to collect quantitative information such as socio-demographic characteristics and indigenous knowledge on conservation; while Focus Group Discussions (FGDs) and Key Informant (KI) interviews were used to collect qualitative data for information triangulation. A total of two FGDs were conducted in two villages whereby each group was comprised by 8 participants and the criteria for selecting them were a person who has sound knowledge on medicinal plants and or a person who is involving in traditional medicines. The key informants' interview involved village leaders whereby seven participants were interviewed in this study. Descriptive statistics were used to analyse the responses regarding indigenous knowledge on conserving medicinal plants. To explore indigenous knowledge on conservation in the community, respondents were required to show their level of agreement on the nine statements based on five responses "Strongly agree, agree, strongly disagree, disagree and neutral". To establish the relationship between demographic parameters and the level of knowledge on conservation of medicinal plants individual score was established based on nine statements of Likert scale. The total scores were used as the proxy for the level of knowledge regarding conservation of medicinal plants. Based on the nine Likert scale statements the cut off score of 27 was established, below which a person is considered having a low indigenous 
knowledge with respect to conservation of medicinal plants, and above which a person is considered as having high indigenous knowledge regarding conserving medicinal plants. The Individual scores were summed up to obtain maximum and minimum scores whereby mean scores were computed based on sex, age group and education level to establish the relationship between demographic characteristics of an individual and indigenous knowledge on conservation of medicinal plants.

\section{Results and Discussions}

\subsection{Indigenous Conservation Knowledge}

The study findings indicated that people in the study area were highly knowledgeable about the traditional fundamentals of medicinal plants conservation. The analysis performed revealed about nine practices that could help in conserving medicinal plant species. Out of the nine indigenous conservation practices, selective harvesting was the most popular in the study area, while, restrictive seasons and times of collecting medicinal plant species was lastly approved by the respondents (Table 1 ).

From the study findings, it was indicated that more than half of the respondents were knowledgeable of a particular indigenous way of conserving medicinal plant species. This shows that the knowledge, practices and beliefs, have all been highly adopted across generations through cultural transmission and in that case, a combination of knowledge has been considered as vital with regards to preserving medicinal plant species in the study area. The sound indigenous knowledge on conservation that was shown by the respondents in Rungwe suggests their awareness of their environment. Similarly, it implies that their long time living in the environment has equipped them with experience that is useful in conservation of medicinal plants. The findings are similar to Mapara (2009) who explain indigenous knowledge systems as a body of knowledge of particular geographical areas which people have survived on for a very long time.

Table 1. Documented indigenous knowledge on conservation.

\begin{tabular}{lcc}
\hline \multicolumn{1}{c}{ Knowledge } & Responses & Percentage \\
\hline 1) Selective harvesting & 274 & 94 \\
2) Planting /domesticating some medicinal plants & 245 & 84 \\
3) Conservation through sacred plants/forests & 243 & 83 \\
4) Keeping names, location and use of some plants secret & 242 & 83 \\
5) Collecting only dead and fallen wood for fuel & 237 & 81 \\
6) Need of having selective morals for harvesters & 214 & 73 \\
7) Using local energy saving stoves & 210 & 72 \\
8) Planting medicinal plants at burial sites & 201 & 69 \\
9) Restrictive seasons and times of collecting medicinal plants & 168 & 57 \\
\hline
\end{tabular}


The relatively higher knowledge score revealed by selective harvesting as a conservation practice could be associated with the advantage the method offers as it allows plants to continue budding. Likewise selective harvesting practice are credited for many areas as indicated in literature such as [1] in West Usambara Mountains' communities, [28] among the Maasai communities and [27] among the Akas tribal group in India. These scholars found almost similar responses that among many practices, selective harvesting was found as the most suitable conservation practice.

Domestication/cultivation of medicinal plant species which came second was attributed by the fact that the practice aids in reducing reliance of medicinal plants on the wild. In support of this study findings reports by [4] [29] commend that cultivation/domestication of medicinal plants are essential in ensuring sustainability of the resources for the present and future generations.

With respect to sacred places and plants, the study indicated that the presence of very strict traditional rules and norms could help to maintain vegetation cover in their areas (sacred places are areas where rituals and sacrifices of a particular community take place). For example, during one of the key informant interviews conducted with one of the traditional elders, the communities in the study area believed on sacredness of forest patches (locally known as masyeto/matongo). If any person interfered with such will result into unexpected heavy rains confined to an area where the offence has been committed. Hence, the elders would search for the criminal and whoever is found guilty is punished by paying a fine of chicken. As a result, these places and plants within are often intact compared to free entry zones. Similar findings associated with respecting sacred areas/plants and their impacts on conservation of plants are confirmed by other scholars [27] [30] [31] who conducted studies in Himalaya and India.

It was indicated that traditional healers and others with knowledge on medicinal plant species have a tendency of concealing information about the plants they know. However, this practice tendency has both negative and positive impacts on conservation. While it could minimize harvesting of the plants since only few people know about these species, it is easy for these few people to destroy the species completely out of ignorance. Studies by [1] in Western Usambara and [32] in Saperas community of Khetawas-India, report similar negative consequences of concealing knowledge about indigenous medicinal plants. The implication of keeping secrets on information about medicinal plants may lead to knowledge disappearance and hence loss to the future generation in the conservation context.

Moreover, the practice of restricting/providing special season for harvesting the plant species was preferred by (57\%) of the many respondents as it provides the plant with ample time to regain its earlier potential or to mature. Although there were no evidence of such species during the survey, the effectiveness of temporary limitations in the gathering of natural products are common to safeguard medicinal plant species [1] [27] [33] [34].

Selective morals for harvesters were also found to score relatively high. 
Their supporting arguments were around species such as Berberisholstii (locally known as Rungwe) which was claimed to require specific morals of the person who want to harvest it. The findings are supported by the knowledge-practice-belief system theory which explains how believing in something may lead to its preservation. Similar findings are also reported by [27] who noted the role of taboos on biodiversity conservation in India.

\subsection{Factors Affecting Indigenous Knowledge on Conservation}

Most times it is perceived that the socio-demographic characteristics of respondents such as age, sex, and education levels could recount for any kind of knowledge on conservation that an individual possesses. Customarily, there has been strong links between age, sex and education level of the person and the indigenous knowledge one has on conservation of medicinal plant species [35]. Relating to this study finding it was showed that age and sex significantly influenced indigenous knowledge on conservation of medicinal plants. However, education levels of the respondents indicated to have no strong relationship with the respondents' indigenous knowledge on conservation (Table 2).

Generally, the study indicated that indigenous knowledge on conservation was highly contributed by the respondents' age increase. The elders revealed relatively higher knowledge to a wider conservation practices than was the case with the youths. This may be attributed to the elders' long-term experience that has been acquired through cultural conservation practices. Further, more than half of the population in the communities in the study area were elders (45 years and above). As perceived to be the main custodians and instructors of cultural practices [35] a similar situation could apply to elders in the study area. Therefore, having larger proportion of elders might guarantee rich indigenous knowledge on conservation and a need to transfer that knowledge to young generations.

Table 2. Socio-demographic attributes and indigenous knowledge on conservation.

\begin{tabular}{ccccc}
\hline Category & Mean score & N & \multicolumn{2}{c}{ Significance } \\
\hline Age group & & & F & P \\
$18-45$ & 36.4496 & 129 & & \\
Above 45 & 39.0549 & 164 & 9.682 & $0.002^{\star *}$ \\
Total & 37.9078 & 293 & & \\
Sex & & & & \\
Male & 38.8889 & 129 & & \\
Female & 37.0696 & 164 & 4.681 & \\
Total & 37.9078 & 293 & & \\
Education level & & & & \\
None & 36.9600 & 25 & & \\
Educated & 37.9963 & 268 & 0.470 & \\
Total & 37.9078 & 293 & & \\
\hline
\end{tabular}


Moreover, it was found that females had lower scores in terms of indigenous knowledge on conservation than was the case with males. However, these results are contrary to the beliefs that traditionally women in rural areas have been thought to be closer to the nature in their daily activities and so they are able to perceive and express more concern about the environment than males [36]. A low knowledge score in females might suggest that the passage of indigenous conservation knowledge favour males than females. But also, in some traditions the knowledge is accompanied by practical experience about the wild environment where females may have limitations because the wild environment is hardly accessible and risky. Despite that, domestication approach may have high influence on the conservation of medicinal plants among females hence a gender balanced conservation approach is encouraged.

The indigenous knowledge on conservation was not attributed to education levels held by the community. This might be due to the fact that indigenous knowledge is not acquired from modern education setup rather through cultural practices and experiences. This suggests that the knowledge is adopted by means of passing it orally from generation to generation. These findings are in contrast with observation of who found education as an important factor influencing indigenous knowledge on conservation. The implication of this finding is that, since formal education may provide people with new discoveries and innovations, there is the possibility of blending the indigenous knowledge with formal training and/or technologies. The two could be instrumental in ensuring a sustained environment for medicinal plant resources.

\section{Conclusion and Recommendations}

Based on the study findings it can be concluded that the community in the study area were rich in indigenous knowledge on conservation of medicinal plant species as they could mention up to nine conservation practices. The conservation practices seemed to be fundamental in conservation of medicinal plant species in the study area. However, the possession of indigenous knowledge of conservation was diverse. The variation of indigenous knowledge revealed by the respondents in Rungwe was influenced by age and sex. Due to these evidences, the study recommends for preservation and promotion of indigenous knowledge on conservation among community members. Further, the study urges for transferring of the knowledge by the elders to the youth.

\section{Acknowledgements}

The author acknowledges the Carnegie Regional Initiative in Science Education-African Natural Products Network (CR-AFNNET) for the financial support that facilitated the execution of this study.

\section{Conflicts of Interest}

The author declares no conflicts of interest regarding the publication of this paper. 


\section{References}

[1] Msuya, T.S. and Kideghesho, J.R. (2009) The Role of Traditional Management Practices in Enhancing Sustainable Use and Conservation of Medicinal Plants in West Usambara Mountains, Tanzania. Tropical Conservation Science, 2, 88-105. https://doi.org/10.1177/194008290900200109

[2] Nimachow, G., Joshi, R. and Dai, O. (2011) Role of Indigenous Knowledge System in Conservation of Forest Resources: A Case Study of the Aka Tribes of Arunachal Pradesh. Indian Journal of Traditional Knowledge, 10, 276-280.

[3] Roberson, E. (2008) Nature's Pharmacy, Our Treasure Chest: Why We Must Conserve Our Natural Heritage, a Native Plant Conservation Campaign Report. 16 p.

[4] Chen, S.L., Yu, H., Luo, H.M., Wu, Q., Li, C.F. and Steinmetz, A. (2016) Conservation and Sustainable Use of Medicinal Plants: Problems Progress and Prospects. Chinese Medicine, 11, Article No. 37. https://doi.org/10.1186/s13020-016-0108-7

[5] Heywood, V.H. (2017) Plant Conservation in the Antropocene-Challenges and Prospects. Journal of Plant Diversity, 39, 314-330. https://doi.org/10.1016/j.pld.2017.10.004

[6] Abdela, G. and Sultan, M. (2018) Indigenous Knowledge, Major Threats and Conservation Practices of Medicinal Plants by Local Community in Hebanarsi District, Oromia, South Eastern Ethiopia. Journal of Advances in Life Science and Technology, 68, 1-20.

[7] Mapara, J. (2009) Indigenous Knowledge Systems in Zimbabwe: Juxtaposing Postcolonial Theory. The Journal of Pan African Studies, 3, 139-155.

[8] Da Silva, N.F., Hanazaki, N., Albuquerque, U.P., Campos, J.L.A., Feitosa, I.S. and De Lima Araújo, E. (2019) Local Knowledge and Conservation Priorities of Medicinal Plants near a Protected Area in Brazil. Journal of Hindawi Evidence-Based Complementary and Alternative Medicine, 2019, Article ID: 8275084.

https://doi.org/10.1155/2019/8275084

[9] Augustino, S. and Gillah, P.R. (2015) Medicinal Plants in Urban Districts of Tanzania: Plants, Gender Roles and Sustainable Use. Forest International Review, 7, 44-58.

[10] World Health Organization (2003) Traditional Medicine Report by the Secretariat. World Health Organization, Geneva.

[11] Mahomoodally, F. M. (2013) Traditional Medicines in Africa: An Appraisal of Ten Potent African Medicinal Plants. Evidence-Based Complementary and Alternative Medicine, 2013, Article ID: 617459. https://doi.org/10.1155/2013/617459

[12] Tabuti, J.R.S., Kukunda, C.B., Kaweesi, D. and Kasilo, O.M.J. (2012) Herbal Medicine Use in the Districts of Nakapiripirit, Pallisa, Kanungu, and Mukono in Uganda. Journal of Ethnobiology and Ethnomedicine, 8, Article No. 35. https://doi.org/10.1186/1746-4269-8-35

[13] Bukuluki, P., Luwangula, R. and Walakira, E.J. (2014) Harvesting of Medicinal Plants in Uganda: Practices, Conservation and Implications for Sustainability of Supplies. International Journal of Medicinal Plant Research, 3, 1-10.

[14] Anyangwe, S.C.E. and Mtonga, C. (2007) Inequities in the Global Health Workforce: The Greatest Impediment to Health in Sub-Saharan Africa. International Journal of Environmental Research and Public Health, 4, 93-100. https://doi.org/10.3390/ijerph2007040002

[15] World Health Organization (2013) Traditional Medicine Strategy. World Health Organization, Geneva, $78 \mathrm{p}$. 
[16] Meremo, A., Mboya, B., Ngilangwa, D.P., Dulle, R., Tarimo, E., Urassa, D. and Ilako, F. (2016) Barriers to Accessibility and Utilization of Hiv Testing and Counselling Services in Tanzania: Experience from Angazazaidi Programme. Pan African Medical Journal, 23, Article No. 189. https://doi.org/10.11604/pamj.2016.23.189.5683

[17] World Health Organization (2015) World Health Statistics. World Health Organization, Geneva, 164-175.

[18] Orisatoki, R.O. and Oguntibeju, O.O. (2010) The Role of Herbal Medicine Use in HIV/AIDS Treatment. Archives of Clinical Microbiology, 1, 1-4.

[19] Chinsembu, K.C. (2016) Ethnobotanical Study of Plants Used in the Management of HIV/AIDS-Related Diseases in Livingstone, Southern Province, Zambia. Evidence-Based Complementary and Alternative Medicine, 2016, Article ID: 4238625. https://doi.org/10.1155/2016/4238625

[20] Kasagana, V.N. and Karumuri, S.S. (2011) Conservation of Medicinal Plants: Past, Present and Future Trends. Journal of Pharmaceutical Sciences and Research, 3, 1378-1386.

[21] Boafo, J. (2013) The Impact of Deforestation on Forest Livelihoods in Ghana. Africa Portal: A Project of the Africa Initiative, $6 \mathrm{p}$.

[22] Food and Agriculture Organization (2010) Global Forest Resources Assessment. Main Report, United Republic of Tanzania, $191 \mathrm{p}$.

[23] Kayombo, E., Mahunnah, R.L.A. and Uiso, F.C. (2013) Prospects and Challenges of Medicinal Plants Conservation and Traditional Medicine in Tanzania. Open Access Journal of Anthropology, 1, 1-8. https://doi.org/10.4172/2332-0915.1000108

[24] Kideghesho, J.R. (2015) Realities on Deforestation in Tanzania-Trends, Drivers, Implications and the Way Forward. In: Zlatic, M., Ed., Precious Forests-Precious Earth, IntechOpen, London. https://doi.org/10.5772/61002

[25] World International Property Organization (2005) Intellectual Property and Traditional Knowledge. WIPO Publication, Geneva, 36 p.

[26] Gadgil, M., Berkes, F. and Folke, C. (1993) Indigenous Knowledge for Biodiversity Conservation. $A M B I O, 22,151-156$.

[27] Nankaya, J. (2014) The Salient Traditional Medicinal Plants and Conservation Strategies of the Loitamaasai of Kenya. Clemson University, Clemson, SC, 7 p.

[28] Wiersum, K.F., Dold, A.P., Husselman, M. and Cocks, M.L. (2006) Cultivation of Medicinal Plants as a Tool for Biodiversity Conservation and Poverty Alleviation in the Amatola Region, South Africa. In: Bogers, R.J., Craker, L.E. and Lange, D., Eds., Medicinal and Aromatic Plants. Agricultural, Commercial, Ecological, Legal, Pharmacological and Social Aspects, Springer, Berlin, 43-57.

[29] Anthwal, A., Amesh, C., Sharman, R.C. and Archana, S. (2006) Sacred Groves: Traditional Way of Conserving Plant Diversity in Garhwal Himalaya, Uttaranchal. The Journal of American Science, 2, 35-38.

[30] Rajendran, S.M. and Agarwal, C. (2007) Medicinal Plants Conservation through Sacred Forests by Ethnic Tribals of Virudhunagar District, Tamil Nadu. Indian Journal of Traditional Knowledge, 6, 328-333.

[31] Panghal, M., Arya, V., Yadav, S., Kumar, S. and Yadav, J.P. (2010) Indigenous Knowledge of Medicinal Plants Used by Saperas Community of Khetawas, Jhajjar District, Haryana, India. Journal of Ethnobiology and Ethnomedicine, 6, Article No. 4. https://doi.org/10.1186/1746-4269-6-4

[32] Kisangau, D.P., Herrmann, T.M., Lyaruu, H., Hosea, K., Joseph, C., Mbwambo, Z. 
and Masimba, P. (2011) Traditional Knowledge, Use Practices and Conservation of Medicinal Plants for HIV/AIDS Care in Rural Tanzania. Ethnobotany Research and Applications, 9, 43-57. https://doi.org/10.17348/era.9.0.43-57

[33] Andarge, E., Shonga, A., Agize, M. and Tora, A. (2015) Utilization and Conservation of Medicinal Plants and Their Associated Indigenous Knowledge (IK) in Dawuro Zone: An Ethnobotanical Approach. International Journal of Medicinal Plant Research, 4, 330-337.

[34] Nakashima, D., Prott, L. and Bridgewater, P. (2000) Tapping into the World's Wisdom. Monthly Information Magazine of the Unesco, No. 125, 11.

[35] Loughland, T., Reid, A., Walker, K. and Petocz, P. (2003) Factors Influencing Young People's Conception of Environment. Journal of Environmental Education Research, 9, 3-20.

[36] Badola, R. Barthwal, S. and Hussain, S.A. (2012) Attitudes of Local Communities towards Conservation of Mangrove Forests: A Case Study from the East Coast of India. Estuarine, Coastal and Shelf Science, 96, 188-196.

https://doi.org/10.1016/j.ecss.2011.11.016 